\title{
Disaster responsive planning: the role of societal forces in implementing software applications
}

\author{
Naduni Wickramaarachchi* , P K S Mahanama \\ Department of Town and Country Planning, University of Moratuwa, Katubedda, Sri Lanka
}

\begin{abstract}
Open source software development is frequently used to serve human society, especially in finding solutions for managing and planning disaster situations such as floods, droughts and tsunami incidents. Careful consideration of the technical accuracy as well as social acceptance is essential to guarantee the sustainability of software development. Understanding the interaction between technology and human behaviour is vital in open source software development in terms of minimizing the negativities after the implementation. The social aspects of software development often being neglected or not being considered well enough in practical filed. The paper discusses the societal factors that can attribute when implementing open source disaster relief management platforms. Humanitarian disaster relief coordination involves some actors with different levels of power and authority. By using theories of multilevel governance and power relations, this paper focuses on understanding the consequences that may arise when implementing common open source platforms, especially in disaster management sector in developing counties. Finally, the article provides recommendations to minimize such obstacles for better functionality and the sustainability of the platform.
\end{abstract}

Keywords: Disaster responsive planning, Humanitarian relief coordination, Multi-level governance, Opensource sotfware

\section{Introduction}

Natural disasters are becoming increasingly common in Sri Lanka. In such situations, complexities arise from a variety of elements, systems, processes and actors, and it is difficult to obtain a clear picture of the entire situation within the timeframe of a crisis. Disaster and post-disaster phases involve stakeholder engagements in different aspects of planning and management, including relief distribution and reconstruction. At the presence of substantial amount of diverse information and data, one of the significant challenge facing by the current humanitarian and disaster relief agencies is the lack of coordination between such agencies during a disaster time (Bharosa, Lee, \& Janssen, 2010; Zhang, Zhou, \& Nunamaker, 2002 ; Abenayake et al., 2018 ).
Exchanging information and sharing responsibilities enhance the effectiveness of responses and improves coordination within the network of responding communities. Poor inter-agency disaster response exchange could negate the disaster response process by impeding efficient collective decision-making and action. Timely and accurate data will enable the government, non-governmental organizations and other volunteers to respond to real crises promptly and effectively. Realtime information will not only assist decisionmakers to take actions but will also enable different users to share and reuse their resources, improve efficiency and reduce wastage.

Open source software solutions are increasingly becoming popular for managing

\footnotetext{
*Corresponding Author

(D) https://orcid.org/0000-0003-1371-9754

Email address : naduniwick@gmail.com

Received 15 May 2019; Received in revised form 27 June 2019 ; Accepted 28 June 2019

DOI: http://doi.org/10.4038/bhumi.v7i1.51
} 
information nowadays (Silva, Warusawitharana, \& Ratnayake, 2017). Disaster relief information management is one of the areas that open source software engineers pay attention to minimise the complications and losses in the current coordination system. The smooth functionality and the sustainability of such systems are questionable because of the unpredictable nature of disasters as well as the un-judgmental nature of human behaviour. Early identifications and predictions of the socio-cultural aspects of using open source technology in similar situations provide vital information on how to develop information management platforms.

The paper provides a review of the social aspects that should be considered in implementing a disaster management information sharing platform. First, it provides a brief justification on the need for a common disaster relief information management system, with a special focus on the current system in Sri Lanka. Then the importance of the open source development as a solution for the disaster relief coordination is discussed. How multilevel governance and power relations come into action at the implementation stage is considered as the theoretical background of the paper. Then the paper presents a review on socio-cultural conditions that may arise in implementing a disaster relief platform guided by some recommendations as the discussion.

\section{Disaster Information Coordination - Need of a Common Information Management Platform}

During a crisis, the unpredictable, dynamic and complex nature of the situation often restricts the sharing and coordination of information between different government and nongovernment organizations and volunteers. The lack of coordination could lead to some potential failures - for example, inappropriate allocations of first responder resources, counter-productive orderings of sequential relief processes, and delayed evacuation leading to higher numbers of causalities and even the loss of lives and livelihoods. Inefficiencies in aid distribution may lead to unnecessary economic losses and increase the poverty level of the country (Gao et al., 2011 ). Instances such as delivering aid supplies that cannot be used or consumed due to religious reasons or the miss-identification of beneficiaries will lead to an increasing communal sense of injustice, frustration, and wasted funding. Ultimately, disaster relief operations are most effective when aid meets the identified needs of the affected community at the correct time. Better information sharing, on the other hand, can lead to improved coordination of disaster responses, and provide an improved outlook for recovery in the long term.

Reports following the Indian Ocean Tsunami in 2004, Hurricane Katrina and the Haiti Earthquake in 2010 provide powerful examples and inform the need for a common information sharing platform for disaster relief management. In the Sri Lankan context, the need for a common disaster management platform has been highlighted by academics, the humanitarian community, and the media (Pathirage, Amaratunge, \& Haigh, 2008; Yates \& Paquette, 2011)

Mostly, in south Asian countries, the responsibility of distributing disaster relief information lies with the national government. In some countries, the humanitarian community made up of local and International Non-Government Organisations (INGOs), and United Nations agencies (Humanitarian Community) are restricted from collecting and disseminating data due to security reasons. Currently, in Sri Lanka, all the donor agencies must rely on the Disaster Management Centers' website to access information during and after a disaster and also use it as points of validation for requesting of international funds. In this backdrop, the Humanitarian Community has to rely on government information, which is sometimes difficult to access and not updated with the ground-realities and also with the realtime data. When faced with an emergency, both managers and responders face a high volume of information which can easily result in cognitive overload at an individual level. Collecting and managing the real-time information and directing that to the relevant decision-makers is 
vitally important in terms of identifying the real problems and needs, to set priorities accordingly, and also to forecast the future situation (Cheng, 2013).

\section{Open source Technology as a Solution}

Open source technology has become the most affordable and attractive solution in the modern world to address and tackle some of the issues facing the world today (Walle, 2007). Open source refers to the source code of software made publicly available with little or no intellectual property restriction. Open source software's source code is freely available for inspection, study and further modification (Mesquita, 2011). Since the software provides the necessary instructions for digital networking and making the source codes more widely available encourages more efficient and rapid development and innovations bringing new products to the market through individual efforts or collaboration. Open source software technology has done a revolutionary change in software development for the betterment of human society.

Free and Open Source Software (FOSS) model has become an essential driving force in finding solutions for different social issues. Using open source software for disaster management and coordination has become increasingly efficient over the past few years. The use of FOSS in disaster management and coordination is fast gain momentum in the world (Pandey, Tyagi, \& Pathak, 2013; Gunarathna et al., 2018; Sudantha ea al.,2018). Although the value of the FOSS is no questionable, the practicality and the sustainability of open source software applications in disaster management sectors raises a question. The ultimate end use of open source development is to build interactions with society. Therefore, the human aspects of software development is an area that should pay serious attention for the sustainability of open source software (Matusita, 2007). Understanding international and intercultural experience in planning and managing different situations is a key factor for success in any innovation (Ratnayake, Butt, \& Budge, 2016). By learning from other practices and become familiar of the context will lead to a sustainable outcome (Ratnayake, Butt, 2017).

\section{Open Source Developments for disaster information coordination}

Even though the natural disasters are increasing at an alarming rate, the core preparedness for the post-disaster responses is still in developing stages. With the new boom of FOSS communities, few initiatives have been introduced in regards to disaster information coordination and relief distribution.

Sahana Disaster Management System development was initially introduced after the Tsunami, 2004 by few Sri Lankan volunteers. At the peak hour of emergency, Sri Lankan government authorized the system as part of the official portal for the centre of national operations: the main body of refill coordination. The system contained, organisation and people registries, the camp registry and request management system, inventory management, messaging and situation mapping. After the Sri Lankan expereince, Sahana was officially deployed in response to the October 2005 Pakistan earthquake, the 2006 Philippine mudslides, and the Yogyakarta earthquake in Indonesia (Benssam, Nouali-Taboudjemat, \& Nouali, 2013).

Ushahidi is another open source disaster management system introduced in 2007. The platform has been deployed in Kenya, Mexico, Afganistan, Haiti, Syria, Venezuela and other places. The app allows integrating data from different sources such as phones, web applications, emails and social media. Ushahidi is not only used for disaster management coordination but also used in many other ways such as sexual harassment reporting and election violence reporting.

All sorts of disaster information sharing platforms have been developed around the world in oder to exchange information and also to set alerts. Global Disaster Alert and Corordination System (www.gdacs.org) is a website that exchanges disaster information in the first pahse after major sudden situation. 
The website presents very recent and acurate information on earthquarks, floods, tropical cyclones, volcanos and droughts around the world. However, it doesnot showcase the needs or dosenot cordinate the disaster relief agencies.

United Nations Office for the Coordination of Humanitarian Affairs (OCHA) provides support to ntional authorities and incountry teams to cordinate the international responses in a major emergency situation. The website shows a summary of OCHA's deployments around the world. Howerver, it doesenot provide the support to cordinate ground level relief distribution.

Although there are several open source platforms in exchanging information during a humanitarian crisis, the functionality on ground level is not an easy task. The ground realities can be vary from country to country, and even it differs within the country depending on the socio-economic layers of the society. Without realising the soci-cultural, economic and governance structures of the society, technological interventions can not be sustained within the society.

\section{Multilevel governance and power relationships}

The theory of multilevel governance is originated in the field of political science and also in the field of public administration. It expresses the idea of interaction between different authority structures. Working with different agencies in a disaster situation creates multi-level relationships among different level of agencies. Understanding how multi-level governance works, therefore, is essential when introducing an online platform to work collaboratively, especially during a disaster. Multi-level governance theory allows picturing the complexity at and between different levels. Jorgensen and Molokken-Ostvold (2004) stressed multilevel governance as an additional burden on introducing information system developments and deployments. In international economic growth, multi-level governance is viewed as multiple levels of governance and participation in the development process. In other words, it is a system of continuous negotiations between different agencies.

Multi-level governance can be formed in two ways: horizontally and vertically. Horizontal dimension refers to co-operation between the same level of institutions and entities. Vertical governance always refers to above and below co-relation among different levels of agencies and organisations (figure 1). When it comes to information technology development, governance between different political entities (national level, sub-national level) and also between different ministries shows an imbalance. It always relays on the complex nature of interdependency. To better functionality of an online platform, there needs to be better governance and flexibility among the agencies.

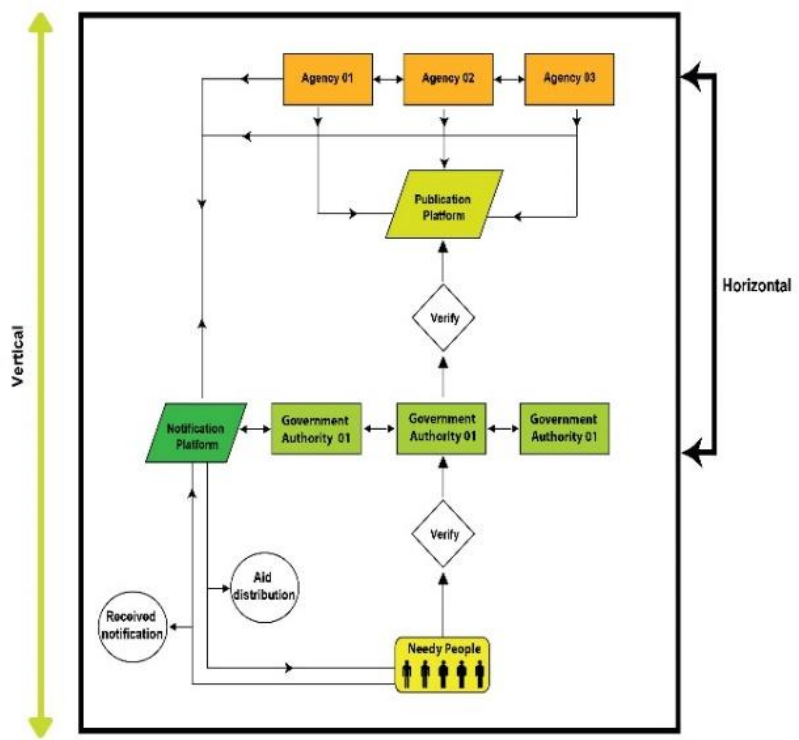

Figure 1: Multilevel governance structure and disaster relief inflormation flow

When it comes to working with the multi-level agencies, one of the aspects that should pay attention to is the power relationship between these agencies. Humanitarian agencies working in developing countries represent a different level of power and authority depending on their wealth and human power. In a hierarchical structure, these agencies can use their power to restrict information flow and block the involvements at the ground level. However, as Foucault (1997) mentions, power can flow in any direction. As a free flow, power can come top to bottom and well as bottom to top. In this 
sense, the ground level small agencies also can act as gatekeepers to block the activities and information flow during a disaster. Therefore, it is essential to view the power relations between different agencies to reduce the complexities that can arise during the implementation stage of a disaster relief coordination platform.

\section{Socio-Cultural Aspects}

Information and knowledge sharing is identified as one of the main bottlenecks faced in the disaster relief community, which hinders information dissemination and effective utilization of available knowledge, which is sometimes even withheld by organisations for profit. For the effective management of the information platform, it is essential to review the societal, economic and political forces that might influence the functioning of the mechanism, to mitigate risks and avoid unexpected interruptions on the ground level.

During a disaster, multiple organizations with different capacities and agendas often act simultaneously at the ground level. This involves a complex network of interdependent agencies, which involves numerous and unpredicted interactions between agencies which can be unique to each situation (Bahaorsa, 2010). At a sudden disaster, there won't be a central body to direct and connect each of the agencies who are working on the ground. Instead, there can be a powerful organisation who comes into the actions and takes the lead in disaster coordination. All of these actions should be predetermined or mutually agreed. However, the agencies who have more power and wealth can dominate the information management system and direct the interactions according to the manifestos which will lead to blocking the other agencies performances and also erase the credit that they should have for their performance on the ground. This situation could lead to competition among organisations. More fundamentally, governance across organisations, across hierarchal levels, and even across technologies could act as barriers to the free flow of information; especially in developing countries, IT governance plays an important role in the functionality of the free flow of information through the internet.

Disaster relief information management involves multi-level governance across and within organizations. These linkages can extend vertically or horizontally: the 'vertical' dimension refers to the linkages between the higher and lower level of institutions, regarding their institutional, financial and informational aspects. The 'horizontal' dimension refers to cooperation between regions and agencies. The hierarchical structures of these agencies impact the flow of information - for instance, it determines who has the authority to access databases (Maldonado \& Maitland, 2010).

During the crisis period itself, how groundlevel actors coordinate their work may depend on authority, power and hierarchical structures, depending on the organization's reputation and scale within the given country. Issues of power and control over the information management may also be intertwined with organizational politics. Thus, managing power aspects, politics and the organizational context of information sharing will be vitally important to the success of the information management system.

In countries like Sri Lanka, government rules and regulations make it hard to work efficiently, especially in a crises situation where a quick response is required. It is questionable who should have the authority to control the main server and the authority to change the formats according to the needs. As the scopes and procedures of disaster management are changing, the format of the data spreadsheet should be modified accordingly. However, the long procedures and the monopoly can create conflicts in interests.

In a crisis, different agencies can work according to their private agendas even though a system provides them with the directions on the needs and the priorities. International Non Government Organisations and NonGovernment Organisations who are working on the ground level may have different visions and priorities according to their portfolios. Such organisations can prioritise their donations 
accordingly, going out of the common intentions. This situation can be worst when it comes to a multi-ethnic environment where different ethnicities segregated in specific locations. As a common platform, it can not tag an organisation and direct them to collaborate. Therfore, it is questionable whether a system could work smoothly as predicted in a multi layered, multi ethnic community.

Lastly, collaboration with multiple organizations is essential to the effective management of an information exchange database. While the overarching goal of all humanitarian agencies is to help citizens, the goals of individual organizations, sub-units of organizations and individual stakeholders may not be aligned. Conflicting goals of interpersonal interests could create issues on the ground, blocking information sharing and any other collaborative work. Humanitarian aid workers also often face severe issues related to time pressure and information overloads. Such complex, rich information easily results in cognitive overload at an individual level.

Resistance to change from the traditional methods of sharing information is a major challenged facing by the FOSS movement in developing countries (Ariyabandu, 2009). With ground-level experience in Sri Lankan context, it is hard to move from the traditional paperbased method to a new online system. The feasibility and the need assessment, therefore, should be the first step before introducing a new online system.

In conclusion, while moving towards to a new phase of humanitarian information sharing, it is vital to review organizational structures, governance structures, multi-organizational relationships, and power and control dynamics among different units, to ensure the effectiveness and the sustainability of the information sharing platform.

7. Discussion: Overcoming barriers to better information coordination during a disaster

Open source technology provides immense benefits for developing countries during emergencies. As open source information exchange platforms have been already developed and customized it does not require an extra cost during an emergency. It offers low cost; volunteer supplemented system to quick employment (Pandey, Tyagi and Pathak, 2013). Software like Sahana is globally available for anyone who desires to use and help during a humanitarian crisis an also provides a transparent platform for inputs and out puts.

As discussed above, it is evident that the new technology has changed countries and their traditional structures, management systems, and flows of information. At the same time, it is obvious that some countries are not at the same level of accepting new technological changes.

The culture of free and open source software relies heavily on community collaboration. The assessment of willingness to change the traditional methods is vital before introducing any technological solution for countries. In this sense, social scientists play a key role in combining social and cultural aspirations with modern software development. Participatory planning tools such as community consultations, surveys, focus group discussions and interviews are essential in understating the people's view to incorporate their perceptions with the development.

As the disaster relief agencies have to work accordingly to the national level legal framework, the government rules and regulations should be considered by the software developers and other agencies. Without proper governmental support, it is hard to introduce such information sharing platforms. Therefore, national level information sharing strategy should be formulated and enforced before the emergency. However, not only the non-government agencies but also the voluntary organization should adhere to the national framework.

The better management of the disaster always relays on a better understanding of the overall situation and also better coordinating with each other. However, during a crucial situation, agencies can limit their attention only to their area of interest without paying much attention 
to the bigger picture. This makes the agencies less aware of and interest in other activities and not responding to urgent needs. To overcome this issue, Baharosa (2010) suggests an incentive system where the agencies get feedbacks and appreciations through an open information management platform.

Information sharing can be considered highly private and confidential in some countries, sometimes during special periods, such as a war situation. This can act as a barrier in sharing information even though an open source software provided the facility to share information. In such situations, open source software developers should work closely with the relevant authorities to not to make threats to the national security.

Most developing countries face physical Information and Communications Technology) challenges when using FOSS, especially within government organisational capacities. Most of the time, the lack of physical ICT infrastructure facilities, low capacities remain as barriers in using information management systems. Therefore, the right assessment of the country's IT capacity is needed before introducing such platforms. Before launching the software applications, thorough sustainability analyses of the product should be carried out by the developers.

Finally, to know the ground level realities and also to make arrangement to overcome these obstacles, there should be an interaction between software development and society. Therefore, public participatory planning methods such as prototype testing should carry out throughout the development process. During the prototype testing period, necessary adjustments can include in to the development.

\section{References}

Abenayake, C.C., Mikami, Y., Matsuda, Y. and Jayasinghe, A., 2018. Ecosystem services-based composite indicator for assessing community resilience to floods. Environmental development, 27, pp.34-46.

Ariyabandu, R. (2009). Free and open source software for disaster management: A case study of Shana disaster management system of Sri Lanka. Retrieved from: http://wiki.sahanafoundation.org/_media/unescap-tech-paper-2009.pdf

Benssam, A., Nouali-Taboudjemat, N., \& Nouali, O. (2013). Towards an IT-Based platform for disaster risk management in Algeria. Paper presented at the ISCRAM conference, Germany.

Bharosa, N., Lee, J., \& Janssen, M. (2010). Challenges and obstacles in sharing and coordinating information during multi-agency disaster response: Propositions from filed exercise. Information Systems Frontiers, 12, 49-65.

Cheng, M.-Y. (2013). Multi-agent based data exchange platform for bridge disaster prevention: a case study in Taiwan. Natural Hazards, 69, 311-326.

Foucault, M. (1997). The subject and power. In J. D. Faubion \& P. Rabinow (Eds.), Power. New York: The New Press.

Gao, H., Wang, X., Barbier, G., \& Liu, H. (2011). Promoting coordination for disaster relief- From crowdsourcing to coordination. Paper presented at the International Conference on Social Computing, Behavioral-Cultural Modeling, and Prediction, Berling.

Gunarathna, B.W.G.I.D., Jayasinghe, A.B., Abenayake, C.C. and Mahanama, P.K.S., 2018. Assessing the impact of land use on triggering landslides: A case of Sabaragamuwa Province, Sri Lanka. Bhumi, The Planning Research Journal, 6(2), pp.15-28. 
Jorgensen, M., Molokken-Ostvold, K. (2004). Reasons for software effort estimation error: impacts of respondent role information collection approach, and data analysis method. IEEE Transactions on Software Engineering, 30(12), 993-1007.

Maldonado, E. A., \& Maitland, C. F. (2010). Collaborative systems development in disaster relief: The impact of multi-level governance. Information Systems Frontiers, 12, 9-27.

Matusita, J. (2007). The implications of the internet for Human Communication. Journal of Information Technology Impact, 7(1), 21-34.

Mesquita, A. (Ed.) (2011). Sociological and philosophical aspects of human interaction with technology: Advancing concepts. ISCAP/IPP and Algoritmi Centre, University of Minho, Portugal.

Pandey, S., Tyagi, V., \& Pathak, K. (2013). Role of open source software and ICT in disaster management. International Journal of Scientific \& Engineering Research, 6(7), 2005-2013.

Pathirage, C. P., Amaratunge, R. D. G., \& Haigh, R. P. (2008). Lessons learned from the Asian Tsunami disaster: Sharing knowledge. Paper presented at the Salford Post Graduate Annual Research Conference, Manchester.

Sudantha, B.H., Warnakulasooriya, K.M.H.K., Jayasuriya, Y.P., Ratnayaka, G.R., Mahanama, P.K.S., Warusavitharana, E.J. and Weerasinghe, S.N., 2018. Open-Source Implementation of an Integrated, Low-Cost Environmental Monitoring System (EMS) for developing countries. Bhumi, The Planning Research Journal, 6(1), pp.23-29.

Ratnayake, R., Butt, A., \& Budge, T. (2016). Planning education and inter-cultural collaboration: awareness, innovation, reflection and preparation for practice. Bhumi: The Planning Research Journal,3(2), 30-43.

Ratnayake,R., Butt, A. (2017). Encounters with unfamiliar: International planning education. International Planning Studies, 23(1), 51-64.

Silva, C., Warusawitharana, E., Ratnayake, R. (2017). An examination of the temporal effects of environmental cues on on pedestrians' feelings of safety. Computers Environment and Urban Systems, 64, 266-274.

Walle, B. V. D. (2007). Open source software for disaster management. Communications of the ACH, 50(1), 61-65.

Yates, D., \& Paquette, S. (2011). Emergency knowledge management and social media technologies: A case study of the 2010 Haitian earthquake. International Journal of Information Management, 31, 6-13.

Zhang, D., Zhou, L., \& Nunamaker, J. F. (2002). A knowledge management framework for the support of decision making in humanitarian assistance/disaster relief Knowledge and Information Sharing, 4, 370-385. 